\title{
Aerosol Management in Dentistry: An Update for Safe COVID-19
}

\section{Clinical Practice}

\author{
Kaur Ishdeep ${ }^{1 *}$, Kaur Arshdeep ${ }^{1}$, Grover Vishakha ${ }^{2}$ \\ Dr. Harvansh Singh Judge Institute of Dental Sciences and Hospital, Panjab University, India \\ Department of Periodontology and Oral Implantology, Dr. Harvansh Singh Judge Institute of Dental Sciences and \\ Hospital, Panjab University, India
}

"Corresponding author: Kaur Ishdeep, Dr. Harvansh Singh Judge Institute of Dental Sciences and Hospital, Panjab University, India. Address: 2401, Sector 38-C, Chandigarh, India. Email: dr.gaurav867@gmail.com, Ph:+1 (408)-6148715

\begin{abstract}
Patient safety and health worker safety from infectious diseases as well as occupational hazards is of utmost importance in every field of medicine. Bioaerosols and splatters generated by air syringes, ultrasonic scalers and high-speed turbine handpieces during dental treatment pose a potential hazard of infection not only to the patients but, to the dentists, dental hygienists, dental assistants as well as other healthcare workers. Severe infectious diseases such as Severe Acute Respiratory Syndrome (SARS), influenza, measles, tuberculosis, hepatitis, HIV AIDS can be transmitted through aerosols. With the emergence of $\beta$-coronavirus (COVID-19), questions concerning the protection from such viral transmission in dental hospital setting have arisen due to close contact and its transmission through the exposure of saliva, blood and other body fluids. Guidelines from regulatory organizations such as $\mathrm{CDC}$ regarding infection control in healthcare settings and infection prevention practices should be strictly followed. A systematic electronic search with relevant key terms viz. Aerosol Management, Dental Aerosols, Dentistry and COVID-19, Dental Unit Waterlines, Preprocedural Mouth rinsing, High Volume Suction Evacuators (HVE) and CDC Guidelines was executed in PubMed and Medline databases for literature extraction and data has been interpreted by including articles based on predefined inclusion criteria .In this review article, we address the importance of understanding and implementation of dental safety by following various systems for management of dental aerosols.
\end{abstract}

Keywords : Aerosols, COVID-19, Dental Unit Waterlines, HVE, CDC

\section{Introduction}

Dental operative procedures including surgeries are performed using a variety of instruments that include air rotor handpieces, ultrasonic scalers and air-water syringes, causing production of bioaerosols and splatter [1]. Before being inhaled by the dental staff and patients, aerosols can float in air for considerable time. Dental aerosols contain microorganisms that are responsible for causing various bacterial diseases, viral infections and other skin infections [2].

A pneumonia outbreak of unknown etiology occurred in $\mathrm{Wu}-$ han, China by the end of 2019. Research has shown that the pathogens of coronavirus were transmitted from animals to humans, which rapidly increased to human-to-human transmission. The pathogen was identified and named as 2019 novel coronavirus (2019- nCoV), and the disease was named coronavirus disease 2019 (COVID-19) [3]. Coronavirus (COVID-19) outbreak was declared as 'Public Health Emergency' on January 30,2020 and further declared as a pandemic on March 11, 2020 by the World Health Organization (WHO) [4]. Since then, the pandemic is rapidly evolving. As confirmed cases are increasing economic development, global health and social stability are continuously decreasing. Apart from COVID-19, diseases like tuberculosis, influenza and mumps can be potentially transmitted via aerosols.

Owing to the characteristics of a dental set-up, the dentist, and other dental office staff are at an extremely high risk to get infected if proper sterilization protocols along with various methods to manage and control the bio-aerosols and splatter are not followed. Students in the dental schools also come in this high-risk category who must be taught about these prevention protocols to minimize the chances of getting an infection or disease.

In this article, we review relevant literature concerning the precautions that need to be taken by dental providers to control and decrease the production of dental aerosols and splatter. We also discuss relevant sources and diseases of airborne contamination along with various methods that should be taken under serious consideration to control the infections that can be spread via dental aerosols and splatter.

\section{Methods of Data Collection}

An electronic research was executed with the use of keywords: Aerosol Management, Dental Aerosols, Dentistry and COVID-19, Dental Unit Waterlines, Preprocedural Mouth rinsing, 
High Volume Suction Evacuators and CDC Guidelines. Articles were studied and selected from PubMed and MEDLINE. Inclusion Criteria for articles included the following information:

-Description of procedures that result in aerosol formation.

-Microorganisms found in aerosols.

-Dental practice in times of COVID-19 and its challenges

-Management procedures for controlling the spread of infection

\section{Dental Aerosols and Splatter}

The terms "aerosol" and "splatter" in the dental environment were first used by Micik and colleagues in their work on aerobiology [5]. Aerosols are defined as particles, which are less than 50 micrometers in diameter [6]. They are suspended in air and are made of solid or liquid particles. Size of the particles can vary from 0.001 to over $100 \mathrm{~mm}$ [6]. The liquid present in aerosol evaporates leaving behind 'droplet nuclei', which contains saliva, dried serum and microorganisms [7]. Research has demonstrated that aerosols can return to baseline 2 hours after the dental treatment $[1,9]$. Also, studies reveal that droplets can contaminate surfaces in a range of 1 -meter ( $3 \mathrm{ft}$ )and stay in the air for a long period of time $[8,10]$. Results from some studies have indicated that aerosols from severe acute respiratory syndrome-coronavirus (SARS CoV) can travel more than six feet [11]. SARS-CoV has limited capacity to survive on a dry surface, several studies have reported that they can persist on a surface for a few days, particularly when suspended in human secretion, and undergo onward transmission [11, 12, 13].

Micik and his colleagues defined splatter as airborne particles that are larger than $50 \mu \mathrm{m}$ in diameter [5]. Splatter is visible to the naked eye and contains a mixture of water, saliva and blood [7] Due to high levels of patient flow, patients as well as dental staff are exposed to aerosols generated from previous treatments and the current treatment being performed on the patient.

\section{Sources of Airborne Contamination}

There are four potential sources of airborne contamination during dental treatment: dental instrumentation, saliva, respiratory sources, and the operative site. Contamination from dental instrumentation is due to organisms present on instruments. Proper sterilization of dental instruments eliminates all kinds of microorganisms and routine disinfection of dental unit waterlines eliminate the growth of biofilm inside the tubes [5].

The human mouth harbors microorganisms from the nose, throat and respiratory tract. It continuously produces saliva, which contains numerous microorganisms. Research demonstrates that the mean level of bioaerosols depends on the specific procedures. Highest aerosol production is seen during the cavity preparation (24-105 CFU/m3), ultrasonic scaling also produces large amounts of aerosols (42-71 CFU/m3) and low levels of aerosols are seen for extraction (9-66 CFU/m3) and for oral examination (24-62 CFU/m3) [1]. Due to increased use of ultrasonic scalers and turbine handpieces air quality in the dental office highly decreases [2]. Due to gravity, larger droplets fall to the ground quickly. On the other hand, small droplets or small particle residues of evaporated droplets have a low settling velocity, so they may remain in the air for a longer time and travel further before they can enter the respiratory tract or contaminate surfaces [5].
Due to high transmissibility of COVID-19 through droplets, and the previous knowledge of dental procedures that generate a significant amount of aerosols, changes should be made in dental practice which are discussed further in this article [14].

\section{Disease Transmission Through an Airborne Route}

Aerosols may contain microorganisms such as multi-resistant Staphylococcus aureus, Influenza virus, Cytomegalovirus, Hepatitis B and C virus, herpes simplex virus Types 1 and 2, Human Immunodeficiency virus etc. [15]. COVID-19 has been detected in health care workers and the number has been increasing since the outbreak.

Streptococcus genus (42\%), Staphylococcus (41\%) and gramnegative bacteria are microorganisms, which were isolated from contaminated surfaces. Non-Diphtheriae Corynebacterium, Staphylococcus aureus, Pseudomonas species and fungi were the microorganisms isolated from the environment of dental clinics [6]. Diseases that can potentially be transmitted via aerosols include common cold, sinusitis, pharyngitis, mumps and fatal diseases like SARS, tuberculosis and influenza. A study conducted by Wang et al. in 2004, in which oral cavity examination of SARS patients was done to determine the viral count. Results showed a large amount of SARS-CoV RNA in their saliva which suggests the possibility of coronavirus transmission through oral droplets [16].

\section{Methods of Reducing Airborne Contamination}

During routine dental practices, guidelines from the Summary of Infection Prevention Practices in Dental Settings produced by the Center for Disease Control and Prevention in the United States (CDC) are followed as "standard precautions" of infection control [17]. Standard precautions are used for all patients under the anticipation that all patients may have a bloodborne infection, such as Hepatitis B virus, hepatitis C virus and HIV. However, due to the concerns of COVID-19, many special precautions should also be taken in dental care settings mentioned by CDC (Guidance for Dental Settings Interim Infection Prevention and Control Guidance for Dental Settings During the COVID-19 Response) to limit the spread [20].

\section{Special considerations during COVID-19}

Despite the large-scale community transmission of COVID-19 during the pandemic, demand for urgent dental treatment decreased by only $38 \%$ [14]. This response shows that even during the time of pandemic, the public need for urgent dental care will always be essential. If the cases are not emergency cases then they can be dealt with tele-dentistry. Dental treatment should be provided only after complete assessment of the patient. Both the risk to the patient of deferring care and the risk to dental health care providers of healthcare-associated disease transmission should be considered.

\section{Waiting area}

Minimum number of patients should be present in the waiting area. Patients should be instructed to cover their nose and mouth with a tissue or their elbow while coughing or sneezing. Patients should be asked to wear masks when they come for dental appointments and chairs should be placed in the waiting area at least $6 \mathrm{ft}$. apart [20]. Patient waiting area should be adequately ventilated. As stated by Atkinson et al. in 2009, for rooms with natural ventilation, $60 \mathrm{~L} / \mathrm{s}$ per patient is considered 
adequate ventilation. Spatial separation of at least $1 \mathrm{~m}$ should be maintained between patients [3]. Equipment such as blood pressure cuffs and thermometers should be cleaned and disinfected with $70 \%$ ethyl alcohol after each use, as recommended by the WHO (2016).

\section{Patient Evaluation}

Patient medical history should be updated during every visit. It should be signed by the patient and reviewed by the dentist before starting dental treatment. It is critical to have a complete medical history in order to make alterations to treatment. Patients must answer targeted screening questions for COVID-19 prior to treatment. These questions should include personal, travel, and epidemiological history. Temperature and lower respiratory tract symptoms should also be noted. Symptoms of fever and fatigue should be closely monitored. If these symptoms are present, then etiology should be known before any further action. For suspected or confirmed cases of COVID-19 that are medically stable, laboratory tests and team consultations should be done. For the safety of patients and healthcare workers, the patient should be rescheduled [14].

As of now, no universal protocol or guideline is available for dental care provision to active or suspected COVID-19 cases. In fact, no universal guidelines are available for dental care provision during the times of any epidemic, pandemic, national or global disaster [14].

Nevertheless, the following methods recommended by CDC and WHO are combined together to achieve the best possible control of infection transmission via aerosols.

1.Hand Hygiene - Hand hygiene is one of the most important aspects of infection control. For routine dental examinations and nonsurgical procedures, the use of water and plain soap or antimicrobial soap should be used.[17] Regular use of an alcohol-based hand rub with greater than $60 \%$ Ethanol or $70 \%$ Isopropanol is recommended by CDC [17]. For surgical procedures, surgical hand scrubbing is recommended as well as sterile surgeon's gloves should be used.

2. Personal Protective Equipment - PPE is specifically designed to protect exposed skin and mucous membranes of healthcare individuals. Skin that can be exposed or are at high risks of contamination are hands, eyes and mouth. Primary PPE used in oral health-care settings includes gloves, surgical masks, protective eyewear, face shields, and protective clothing (e.g., gowns and jackets) [18].

Protective Eyewear - Protective Eyewear should be used at all times while performing procedures as most of the dental procedures generate aerosols. Reusable PPE should be meticulously cleansed with soap and water [18]. It should be disinfected properly in between patients.

Masks - Masks are usually the most contaminated areas with aerosol and splatter during a dental procedure. Masks should be protective enough and should cover the nose as well as the mouth properly. Masks also protect from large-particle droplet spatter, which might contain pathogens like hepatitis B or other infectious microorganisms. Bacterial filtration efficiency of surgical masks is $>95 \%$. These masks are called N95 as they can filter $1-\mu \mathrm{m}$ particles in the unloaded state with a filter efficiency of $>95 \%$ (i.e., filter leakage $<5 \%$ ), given flow rates of $<50 \mathrm{~L} / \mathrm{min}[18]$. o

Masks should not be touched during procedures with contaminated hands. In cases of COVID-19 and tuberculosis; National Institute for Occupational Safety and Health (NIOSH)-certified particulate-filter respirator such as; N95, N99, or N100 should be used [18].

Gloves- Gloves are worn to protect contamination of healthcare workers' hands when touching mucous membranes, blood, saliva. If gloves are torn or punctured; they should be changed as soon as possible. Task specific gloves of correct size should be worn for proper protection. Most importantly, gloves should cover the wrist of isolation gowns. Sterile surgeon's gloves must meet standards for sterility assurance approved by FDA [19].

Face Shields - In this time of coronavirus outbreak, face shield should be worn by the dentists, dental hygienists as well as dental assistants during procedures and patient care activities that generate aerosol and splatter of body fluids, blood or saliva. [20]Face Shields should be cleaned with disinfectant between patients. It is also important to use a face shield that covers the forehead, side of the face and below the chin properly [18].

Protective Clothing - It covers the skin, hair, shoes and personal clothing. OSHA bloodborne pathogens standard requires sleeves to be long enough to protect the forearms when the gown is worn as PPE [18]. All protective clothing including lab coats and surgical gowns should be removed before leaving the work area [18].

Ensure that the appropriate amount of personal protective equipment (PPE) and supplies to support the patient volume is available. If PPE and supplies are limited, prioritize dental care for the highest need, most vulnerable patients first [20].

3. Dental Unit Waterline (DUWL) Sterilization - Dental unit waterlines are 3-4 m flexible, narrow tubes made of plastic material connected to the Dental Chair Unit (DCU) which supplies water to ultrasonic scalers, dental handpieces and threeway air or water syringes [25]. The inside surface of the tube enhances the formation of biofilm due to narrow diameter that causes water stagnation [21]. When the handpieces or scalers are used, the biofilm-coated untreated dental unit waterlines allow the microorganisms to disperse through the water network and allows the pathogens into the environment through aerosolization of dental water from the dental equipment.[22] More than forty species were identified from the dental unit waterline biofilms and the main pathogenic organisms were Gram-negative bacteria which produce endotoxins and can cause fever, mild inflammation to septic shock [23,24].

Snophia et al., in 2011 reported two patients contaminated with Pseudomonas Aeruginosa when treated in a dental clinic, where DUWLs was the source of infection. The microorganisms that were isolated from the oral abscess developed in these patients was the same strain isolated from the DUWLs [7].

The CDC recommends that dental unit water used in nonsurgical procedures measure less than or equal to 500 colony forming units of heterotrophic bacteria per milliliter $(\leq 500 \mathrm{CFU} /$ $\mathrm{mL}$ ) of water, the standard set for drinking water by the Environmental Protection Agency (EPA) [18].

Flushing the handpiece is a common practice, done to reduce the microbial count in the dental unit waterlines [25]. The FDA recommends flushing all water lines for at least 20-30 seconds after each patient. It reduces the microbial content in the dental water but the biofilm still exists adhering to the inner wall of the dental unit waterlines, which continues contaminating the 
incoming water $[26,27]$. Another approach is to improve the quality of DUWL output water is by using sterile, distilled or deionized water in DCU reservoir bottles. Draining DUWLs after use and drying them with pressurized air has also been attempted, but following reconnection of DUWL to the water supply, microorganisms still remain viable in the biofilm. Fitting microbial filters to DUWLs near the dental instrument attachment sites can improve the quality of water but the disadvantage is that they get clogged frequently and do nothing to the already existing biofilm [28].

A study was conducted by Shajahan and colleagues in 2016, in which $200 \mathrm{ml}$ of hypochlorous based disinfectant was made to run through the dental chair unit system and was allowed to remain in the water lines. Based on the result obtained from SEM, it was concluded that usage of disinfectant was found to be effective in the removal of biofilm. Various other disinfectant solutions that are used include hydrogen peroxide, chlorhexidine gluconate, Listerine mouthwash, povidone-iodine and electrochemically activated water [29].

4. High Volume Suction Evacuators-During the times of COVID-19, limitations should be imposed on using dental handpieces, ultrasonic scalers, air-water syringes due to the production of aerosols. Priority should be given to minimally invasive/atraumatic restorative techniques (hand instruments only) [20]. However, if necessary, in emergency cases, four handed dentistry should be used effectively and high-volume suction evacuators must be used to reduce the aerosol in the environment [20].

From a practical point of view, it is easiest to remove as much airborne contamination as possible before it escapes the immediate treatment site. The use of a high-volume evacuator, or HVE, has been shown to reduce the contamination arising from the operative site by more than 90 percent [30]. For a suction system to be classified as an HVE, a large volume of air must be removed by it in a short period of time. The usual HVE used in dentistry has a large opening (usually 8 millimeters or greater) and is attached to an evacuation system removes a large volume of air (up to 100 cubic feet of air per minute) [5]. The small opening of a saliva ejector does not remove a large enough volume of air to be classified as an HVE [5].

A recent study by Desarda et al. suggests that a high-volume evacuator when used as a separate unit without any modification, is not effective in reducing aerosol counts and environmental contamination. Statistical analysis clearly demonstrated that there was no significant difference in the number of CFUs when a HVE is used versus when it isn't [30]. These results were in contrast to King et al, who found that ultrasonic scaler without the aerosol reduction device (ultrasonic scaler alone) had a significantly greater quantity of mean colony forming units (CFUs) 6 inches from the subject's oral cavity than the ultrasonic scaler with the aerosol reduction device (i.e, combination of HVE and ultrasonic scaler). The differences in the results might be attributed to the fact that King et al. used modified devices which may have blocked the splatter from reaching the agar plates [31].

Muzzin et al. in their in vivo study used a modified device consisting of a high-volume evacuator and an air polisher as a single unit and reported contrasting results showing an $86 \%$ reduction in CFU [32]. In another study, Yamada et al. evaluated the effect of high-volume evacuators in reducing aerosol blood mist. The study showed that the use of double extraoral high-volume evacuator systems was more beneficial in reducing aerosol blood mist as compared to single extraoral evacuator systems [33]. These studies showed that a modified HVE system is effective in reducing the aerosol cloud significantly.

5. Preprocedural mouth rinsing- Mouth Rinsing is one of the most effective ways used to reduce the microbial count in the oral cavity. Preprocedural mouth rinses are used to decrease the number of microorganisms in the dental aerosol, which ultimately helps in the reduction of aerosol contamination in office [34].

A meta-analysis showed that the use of preprocedural mouth rinse resulted in a mean reduction of $68.4 \%$ colony-forming units in dental aerosol [34]. Some of the preprocedural mouth rinses used in practices are Povidone Iodine [35], chlorhexidine (CHX) [36], cetylpyridinium chloride (CPC) [37], and essential oils (EO) [38]. A study conducted by Domingo and colleagues, in which $20 \mathrm{~mL}$ of $1 \%$ Povidone Iodine was used by the patients to rinse the oral cavity before proceeding with the procedure. This showed bactericidal effect in the microorganism concentration resulting in reduction of gingival surface flora up to four hours [35]. Veksler et al. has also demonstrated reduced micro-organisms in gingiva before oral prophylaxis with ultrasonic scalers with $0.12 \%$ chlorhexidine (CHX) gluconate $[39,40]$. However, the effect of preprocedural mouth rinse against coronavirus is still not known [24].

6. High Efficiency Particulate Air Filters - Air purifiers with high-efficiency particulate filters remove particulate matter as well as microorganisms in the indoor environment [41]. These are flat and pleated filters used to mechanically filter the airborne particles. These filters have a very thin glass fiber woven into a paper like material. It is standardized at a minimum $99.97 \%$ efficiency rating for removing particles greater than or equal to $0.3 \mu \mathrm{m}(1 / 83,000$ of an inch) in diameter [42].

Maus et al. (2001) studied the effect of the filters on removal of micro-organisms. It was reported that microbes could stay viable in the filters for a long period of time and may enter back into the filtered air. The filter forms a more favorable environment for the microorganisms to grow [43]. Another drawback of HEPA filters is that they are extremely expensive due to high energy cost which is required for powerful fans to generate sufficient airflow through the filter to eventually clean the indoor air [42].

WHO (2020a) has recommended the use of a negative pressure room with a minimum of 12 air changes per hour or at least 160 $\mathrm{L} / \mathrm{s}$ per patient for facilitating natural ventilation? Mechanical ventilation should begin before treating the next patient. The use of these units will reduce particle count including droplets in the room [20].

7. Rubber Dam Isolation: The rubber dam is a disposable rubber sheet that is stretched around the treated tooth or teeth which isolates the treatment zone from saliva. The use of a rubber dam during restorative and endodontic treatments is considered the standard of care in most dental care-providing clinics and hospitals. Its use has been associated with higher rates of dental treatment success [44]. Additionally, Cochran et al. and Samaranayake et al., in two separate studies, observed a significant reduction in bacterial atmospheric contamination when rubber dams were used $[45,46]$. However, rubber dam isolation may not be possible at all times like at end stage tooth 
preparation or bone cutting during surgical extractions. But the use is recommended whenever possible.

\section{Sterilization and disinfection of rooms and dental equip-} ment- Rooms should be cleaned and disinfected after every procedure has been done on a patient. Wipe, spray and wipe technique should be used to clean all the exposed surfaces in the room including $\mathrm{x}$-ray machines, dental chairs, dentist's and assistants' chairs, computer, eyewear and dental equipment used. Routine cleaning and disinfection procedures (e.g., EPA-registered, hospital-grade disinfectant) should be used for SARS-CoV-2 in healthcare settings [20].

Depending on the risk for infection associated- dental instruments, devices, and equipment can be listed further as critical, semi critical, or noncritical [18].

o Critical items are defined as items that enter the soft tissue. These items must be sterilized with heat because they have the highest risk of transmitting or containing infections [18]. Ensure that the sterilizers are working properly by using biological indicators especially after a period of non-use prior to reopening [20].

o Semi Critical patient care items touch mucous membranes and intact skin. These items have a low transmission risk of infection. If a semi critical item is heat-sensitive, it should thoroughly be cleaned with high-level disinfectant [18]. o Noncritical items touch intact skin and are least susceptible to causing infection. If the item is visibly contaminated with blood or saliva then EPA-registered hospital disinfectant with a tuberculocidal claim should be used $[47,48]$.

\section{Conclusion}

Due to the nature of dentistry, dental professions are at a higher risk of getting infected with airborne diseases. Also, with the rising concern of COVID-19 and it's spread through aerosols, standard precautions as well as new additions to the precautions should be thoroughly followed and applied by the dental team on an everyday basis. To confirm patient and provider safety, oral health professionals should accept and imply the latest $\mathrm{CDC}$ guidelines and recommendations related to $\mathrm{CO}-$ VID-19. In addition to sterilization of dental instruments and using personal protective equipment, combining multiple methods for management of dental aerosols is the most effective approach. The use of High-Volume Suction Evacuators is highly effective in minimizing the spread of aerosols in the environment and preprocedural mouth rinsing with Povidone Iodine or Chlorhexidine in reducing the microbial count in the saliva. Sterilization and maintenance of Dental Unit Waterlines (DUWLs) should be routinely performed by using a high-grade disinfectant such as hypochlorous acid or hydrogen peroxide. Disinfection of dental operatory must be done after every patient, made as easy as possible and should extend to all contaminated areas. In general, dental offices should be seen as operation theatres in order to reduce the risks of transmission of infections.

\section{Funding}

This research did not receive any specific grant from funding agencies in the public, commercial, or not-for-profit sectors.

\section{Conflict of Interest}

The authors declare no conflict of interest

\section{Ethical approval}

Not applicable

\section{References}

1. Kobza J, Pastuszka JS, Bragoszewska E. Do exposures to aerosols pose a risk to dental professionals. OCCUP MED-OXFORD. 2018; 68(7): 454-458.

2. Sawhney A, Venugopal S, Babu GR, Garg A, Mathew M, Yadav $\mathrm{M}$, et al. Aerosols how dangerous they are in clinical practice. J. Clin. Diagn. Res. 2015; 9(4): ZC52-ZC57.

3. Ge ZY, Yang LM, Xia JJ, Fu XH, Zhang YZ. Possible aerosol transmission of COVID-19 and special precautions in dentistry. J Zhejiang Univ Sci B. 2020; 1-8.

4. Meng L, Hua F, Bian Z. Coronavirus Disease 2019 (COVID-19): Emerging and Future Challenges for Dental and Oral Medicine. J. Dent. Res. 2020; 99(5): 481-487.

5. Harrel SK, Molinari J. Aerosols and splatter in dentistry: a brief review of the literature and infection control implications. J Am Dent Assoc. 2004; 135(4): 429-437.

6. Raghunath N, Meenakshi S, Sreeshyla HS, Priyanka N. Aerosols in dental practice: a neglected vector. Br. Microbiol. Res. J. 2016; 14(2): 1-8.

7. Swaminathan Y, Thomas JT. Aerosol: a prospective contaminant of dental environment. IOSR JDMS. 2013; 11(2):.45-50.

8. Zemouri C, de Soet H, Crielaard W, Laheij A. A scoping review on bio-aerosols in healthcare and the dental environment. PLoS One. 2017; 12(5): e0178007.

9. Dutil S, Meriaux A, de Latremoille MC, Lazure L, Barbeau J, Duchaine C. Measurement of airborne bacteria and endotoxin generated during dental cleaning. J Occup Environ Hyg, 2009; 6: 121-130.

10. Barker J, Jones MV. The potential spread of infection caused by aerosol contamination of surfaces after flushing a domestic toilet. J Appl Microbiol. 2005; 99(2): 339-47.

11. Kutter JS, Spronken MI, Fraaij PL, et al. Transmission routes of respiratory viruses among humans. CurrOpinVirol, 2018; 28: 142-151.

12. Kramer A, Schwebke I, Kampf G. How long do nosocomial pathogens persist on inanimate surfaces? A systematic review. BMC Infect Dis, 2006; 6: 130.

13. Otter JA, Yezli S, Salkeld JAG, et al. Evidence that contaminated surfaces contribute to the transmission of hospital pathogens and an overview of strategies to address contaminated surfaces in hospital settings. Am J Infect Control. 2013; 41(5): S6-S11.

14. Alharbi A, Alharbi S, Alqaidi S. Guidelines for dental care provision during the COVID-19 pandemic. Saudi Dent J. 2020; 32(4):181-186.

15. James R, Mani A. Dental aerosols: a silent hazard in dentistry. Int. J. Sci. Res. 2015; 5(11): 1761-1763

16. Doremalen V, Bushmaker N, Morris T, Holbrook DH, Gamble MG, Williamson A, et al. Aerosol and surface stability of SARSCoV-2 as compared with SARS-CoV. N Engl J Med. 2020; 382: 1564-1567.

17. Centers for Disease Control and Prevention. Summary of Infection Prevention Practices in Dental Settings: Basic Expectations for Safe Care. Atlanta, GA: Centers for Disease Control and Prevention, US Dept of Health and Human Services; October2016. Available at https://www.cdc.gov/oralhealth/infectioncontrol/ pdf/safe-care2.pdf.

18. Centers for Disease Control and Prevention. Guidelines for infection control in Dental Health Care settings. MMWR. 2003;55(RR17):1-61 https://www.cdc.gov/mmwr/preview/ mmwrhtml/rr5217a1.html.

19. Food and Drug Administration. Glove powder report. Rockville, MD: US Department of Health and Human Services, Food and Drug Administration, 1997. Available at http://www.fda.gov/ cdrh/glvpwd.html.

20. Centers for Disease Control and Prevention. Coronavirus Disease 2019: guidance for dental settings. 2020. Available at https:// www.cdc.gov/coronavirus/2019-ncov/hcp/dental-settings.html

21. Barbeau J, Nadeau C. Dental unit waterline microbiology: A cautionary tale. J Can Dent Assoc. 1997; 63:775-779.

22. Coleman DC, O'Donnell MJ, Shore AC, Russell RJ. Biofilm problems in dental unit water systems and its practical control. J 
Appl Microbiol. 2009; 106:1424-1437.

23. Singh R, Stine OC, Smith DL, Spitznagel JK, Jr, Labib ME, Williams HN. Microbial diversity of biofilms in dental unit water systems. Appl Environ Microbiol. 2003; 69: 3412-3420.

24. Dutil S, Meriaux A, de Latremoille MC, Lazure L, Barbeau J, Duchaine C. Measurement of airborne bacteria and endotoxin generated during dental cleaning. J Occup Environ Hyg. 2009; 6: $121-30$.

25. Watanabe E, Agostinho AM, Matsumoto W, Ito I. Dental unit water: Bacterial decontamination of old and new dental units by flushing water. Int J Dent Hyg. 2008; 6: 56-62.

26. Barbeau J, Gauthier C, Payment P. Biofilms, infectious agents, and dental unit waterlines: A review. Can J Microbiol. 1998; 44: $1019-1028$.

27. Lee TK, Waked EJ, Wolinsky LE, Mito RS, Danielson RE. Controlling biofilm and microbial contamination in dental unit waterlines. J Calif Dent Assoc. 2001; 29: 679-684.

28. O'Donnel MJ, Boyle MA, Russel JR, Coleman DC. Management of dental unit waterline biofilm in the 21 st century. Future Microbiol. 2011; 6(10):1209-1266.

29. Shajahan IF, Kandaswamy D, Srikanth P, Narayana LL, Selvarajan R. Dental unit waterlines disinfection using hypochlorous acid-based disinfectant. J Conserv Dent 2016; 19: 347-350.

30. Desarda H, Gurav A, Dharmadhikari C, Shete A, Gaikwad S. Efficacy of High-volume Evacuator in Aerosol Reduction: Truth or Myth? A Clinical and Microbiological Study. J Dent Res Dent Clin Dent Prospects. 2014; 8(3): 176-179.

31. King TB, Muzzin KB, Berry CW, Anders LM. The effectiveness of an aerosol reduction device for ultrasonic scalers. J Periodontol. 1997; 68: 45-49.

32. Muzzin KB, King TB, Berry CW. Assessing the clinical effectiveness of an aerosol reduction device for the air polisher. J Am Dent Assoc. 1999; 130: 1354-1359.

33. Yamada H, Ishihama K, Yasuda K, Nakayama H, Shimoji S, Furusawa K. Aerial dispersal of blood-contaminated aerosols during dental procedures. Quintessence Int. 2011; 42: 399-405.

34. Marui VC, Souto MLS, Rovai ES, Romito GA, ChambroneL, Pannuti CM. Efficacy of preprocedural mouthrinses in the reduction of microorganisms in aerosol: a systematic review. J Am Dent Assoc. 2019; 150(12): 1015-1026.

35. Domingo MA, Farrales MS, Loya RM, Pura MA, Uy H. The effect of $1 \%$ povidone iodine as a pre-procedural mouthrinse in 20 patients with varying degrees of oral hygiene. J Philipp Dent Assoc. 1996; 48(2): 31-38.
36. Van Strydonck DA, Slot DE, Van der Velden U, Van der Weijden F. Effect of a chlorhexidine mouthrinse on plaque, gingival inflammation and staining in gingivitis patients: a systematic review. J Clin Periodontol. 2012; 39(11): 1042-1055.

37. Haps S, Slot DE, Berchier CE, Van der Weijden GA. The effect of cetylpyridinium chloride-containing mouth rinses as adjuncts to toothbrushing on plaque and parameters of gingival inflammation: a systematic review. Int J Dent Hyg. 2008; 6(4): 290-303.

38. Araujo MWB, Charles CA, Weinstein RB, et al. Meta-analysis of the effect of an essential oil-containing mouthrinse on gingivitis and plaque. JADA. 2015; 146(8): 610-622.

39. Kaur R, Singh I, Vandana KL, Desai R. Effect of chlorhexidine, povidone iodine, and ozone on microorganisms in dental aerosols: randomized double-blind clinical trial. Indian J Dent Res. 2014; 25(2): 160-165.

40. Veksler AE, Kayrouz GA, Newman MG. Reduction of salivary bacteria by pre-procedural rinses with chlorhexidine $0.12 \%$. J Periodontol, 1991; 62: 649-651.

41. Guo J, Xiong Y, Kang T, Xiang Z, Qin C. Bacterial community analysis of floor dust and HEPA filters in air purifiers used in office rooms in ILAS, Beijing. Sci Rep. 2020; 10(1): 6417.

42. Fox RW. Air cleaners: a review. J Allergy Clin Immunol. 1994; 94: 413-416.

43. Pokhum C, et al. A facile and cost-effective method for removal of indoor airborne psychrotrophic bacterial and fungal flora based on silver and zinc oxide nanoparticles decorated on fibrous air filter. Atmos. Pollut. Res. 2018; 9: 172-177.

44. I.A. Ahmad Rubber dam usage for endodontic treatment: a review. Int Endod J, 2009; 42: pp. 963-972.

45. Cochran MA, Miller CH, Sheldrake MA. The efficacy of the rubber dam as a barrier to the spread of microorganisms during dental treatment J Am Dent Assoc. 1989; 119: 141-144.

46. Samaranayake LP, Reid J, Evans D. The efficacy of rubber dam isolation in reducing atmospheric bacterial contamination. ASDC J Dent Child 1989; 56: 442-444.

47. Rutala AW, Weber JD. The Healthcare Infection Control Practices Advisory Committee (HICPAC). Guideline for disinfection and sterilization in healthcare facilities. 2008. Available at https://www.cdc.gov/infectioncontrol/guidelines/disinfection/

48. CDC. Guidelines for environmental infection control in healthcare facilities: recommendations of $\mathrm{CDC}$ and the Healthcare Infection Control Practices Advisory Committee (HICPAC). MMWR 2003;52(No. RR-10). 